\title{
POTENSI TERNAK SAPI POTONG, SAPI PERAH DAN KERBAU SEBAGAI PENGHASIL DAGING DI KABUPATEN NUSA TENGGARA TIMUR
}

\author{
SUKADA, I K., I W. SUBRATA, DAN I G. SUARTA \\ Fakultas Peternakan Universitas Udayana Denpasar Bali \\ e-mail: ketut_sukada888@yahoo.com
}

\begin{abstract}
ABSTRAK
Provinsi Nusa Tenggara Timur yang sering dijuluki sebagai lumbung sapi potong sapi perah dan kerbau. Dipandang dari sudut luas lahan yang dikuasai oleh rumah tangga antara lain lahan bukan pertanian, lahan pertanian yaitu lahan sawah dan lahan bukan sawah seluas. Penelitian dilakukan terbatas pada tiga buah kabupaten di NTT yaitu Kupang, Timor Tengah Selatan (TTS) dan Belu. Hasil penelitian menunjukkan hubungan matematika antara lahan pangan $(\mathrm{X})$ terhadap populasi sapi potong $(\mathrm{Y})$ didapatkan: $\mathrm{Y}=110,2324+1,7048 \mathrm{X}$ dan $\mathrm{R}^{2}$ $=0,9838(\mathrm{P}<0,01)$. Hubungan matematika antara lahan perkebunan $(\mathrm{X})$ terhadap populasi sapi potong $(\mathrm{Y})$ adalah: $\mathrm{Y}=116,5996+2,4735 \mathrm{X}$ dan $\mathrm{R}^{2}=0,9833(\mathrm{P}<0,01)$. Hubungan matematika antara lahan hortikultural $(\mathrm{X})$ terhadap populasi sapi potong $(\mathrm{Y})$ tidak berbeda nyata $(\mathrm{P}>0,05)$. Nilai Location Quotien terbesar pada kerbau terdapat di Kabupaten Kupang 6,2920, selanjutnya nilai LQ untuk kerbau di Kabupaten Timor Tengah Selatan sebesar 4,9411 dan nilai LQ untuk kerbau di Kabupaten Belu sebesar 2,0762. Nilai LQ untuk sapi perah terbesar 1,4577 ditemukan di Kabupaten Timor Tengah Selatan. Hasil penelitian ini dapat disimpulkan bahwa populasi ternak potong terhadap lahan pangan dan perkebunan berhubungan positif sangat nyata $\left(R^{2}=0,98 P<0,01\right)$. Nilai $L Q$ ternak kerbau terbesar berturut-turut didapatkan di Kabupaten Kupang, TTS dan Belu sehingga dapat dijadikan sentra ternak kerbau untuk daerah-daerah lain di Provinsi NTT. Begitu juga untuk ternak perah di Kabupaten Timor Tengah Selatan dapat dijadikan sentra ternak karena lebih besar dari satu.
\end{abstract}

Kata kunci: location quotien, ruminansia, lahan pangan, hortikultura, perkebunan

\section{THE POTENTIAL OF CATTLE, DAIRY CATTLE AND BUFFALO AS MEAT PRODUCER AT NUSA TENGGARA TIMUR}

\begin{abstract}
East Nusa Tenggara Province is commonly called as the cattle ruminant livestock cattle for slaughter, dairy cattle, and buffalo. The extensive land owned by household as of non-agricultural land, wet land, and rice field. The research was conducted at three districts as of: Kupang district, Timor Tengah Selatan District, and Belu with ruminants reared at cropland, horticultural, and plantation. The results showed that mathematics relationship between cropland $(\mathrm{X})$ and beef cattle population $(\mathrm{Y})$ is $\mathrm{Y}=110.2324+1.7049 \mathrm{X}$ and $\mathrm{R}^{2}=0.9838(\mathrm{P}<0.01)$. Mathematics relationship between plantation area $(\mathrm{X})$ and beef cattle population $(\mathrm{Y})$ is $\mathrm{Y}=116.5996+2.4735 \mathrm{X}$ and $\mathrm{R}^{2}=0.9833$ $(\mathrm{P}<0.01)$. Mathematics relationship between horticultural land $(\mathrm{X})$ and beef cattle population $(\mathrm{Y})$ not significantly different (P>0.05). The Location Quotien value of the buffalo at Kupang is 6.2920, meanwhile the buffalo value of LQ at TTS district is 4.9411 and LQ for buffalo at Belu is 2.0762, and 1.4577 of dairy cows as the highest LQ were found at Timor Tengah Selatan district. The results showed that livestock population on cropland and plantation were positively related $\left(\mathrm{R}^{2}=0.98 \mathrm{P}<0.01\right)$. The LQ value of buffaloes successively obtained at Kupang district, TTS, and Belu. In this case, it can be used as the center of buffalo commodities with other areas at Nusa Tenggara Timur (NTT). These can also be arranged for dairy cattle at Timor Tengah Selatan district to be the center of livestock.
\end{abstract}

Keywords : location quotien, ruminants, cropland, horticultural, plantation

\section{PENDAHULUAN}

Ketidakmampuan produksi peternakan dalam negeri untuk memenuhi kebutuhan domestik adalah berkurangnya luas lahan pertanian akibat alih fungsi la- han pertanian kesektor lain, menurunnya minat petani untuk bertani dan beternak akibat pengaruh sektor lain yang lebih menjanjikan kehidupan dan yang terpenting adalah lemahnya sumber daya manusia dalam menguasai ilmu pengetahuan dan teknologi. Suryana (2000), 
mengatakan bahwa ketidak mampuan produksi peternakan dalam negeri untuk memenuhi kebutuhan domestik dipengaruhi oleh beberapa keterbatasan antara lain: (a) penguasaan teknologi, baik di bidang produksi maupun penanganan pasca panen, (b) kemampuan permodalan peternakan, (c) kualitas sumberdaya manusia, dan (d) ketersediaan pakan.

Provinsi Nusa Tenggara Timur merupakan kawasan Timur Indonesia yang memiliki populasi ternak ruminansia besar cukup banyak sehingga sering dijuluki sebagai lumbung ternak. Wilayah NTT mungkin cocok menerapkan sistem itegrasi padi ternak yang merupakan upaya peningkatan produksi daging ternak potong yang sekaligus upaya peningkatan produksi pangan melalui kegiatan pemeliharaan sapi pada daerah lahan tanaman pangan beririgasi mendukung kebutuhan daging nasional (Yusdja et al., 2004). Noor (2004) dalam seminar Pengembangan Peternakan Berwasasan Lingkungan di IPB, mengatakan bahwa kegiatan sistem integrasi pertanian terpadu adalah sistem pertanian yang ramah lingkungan yang berkesinambungan, mengoptimalkan pemanfaatkan sumberdaya yang ada,menjaga dan meningkatkan kesehatan manusia, serta melindungi lingkungan dan menghasilkan bahan makanan yang cukup bagi penduduk. Artinya 2/3 dari penduduk miskin di negara-negara berkembang memelihara ternak sapi dan hampir 60\% diantaranya bergantung pada sistem tanaman-ternak. Hasil Sensus Pertanian Provinsi Nusa Tenggara Timur tahun 2013 luas lahan bukan pertanian $396,19 \mathrm{~m}^{2}$ dan luas lahan pertanian antara lain: luas lahan sawah: $1.228,38 \mathrm{~m}^{2}$, luas lahan bukan sawah: $7.616,50 \mathrm{~m}$, jumlah rumah tangga yang mengusahakan subsektor tanaman pangan sebanyak: 701.852 orang, subsektor hortikultura sebanyak: 426.970 orang dan sub sektor perkebunan sebanyak: 581.242 orang. Jumlah sapi dan kerbau tercatat sebanyak 936.611 ekor, terdiri dari: 803.450 ekor sapi potong, 39 ekor sapi perah dan 133.122 ekor kerbau. Kabupaten Nusa Tenggara Timur yang mempunyai jumlah sapi dan kerbau terbanyak adalah Kabupaten Timor Tengah Selatan (TTS), dengan jumlah sapi dan kerbau sebanyak 162.342 ekor. Sedangkan Kabupaten Flores Timur adalah kabupaten dengan jumlah sapi dan kerbau paling sedikit: 1.939 ekor. Jumlah sapi potong terbanyak terdapat di Kab. TTS, yaitu sebanyak 161.990 ekor, demikian halnya dengan jumlah sapi perah terbanyak yaitu sebanyak 28 ekor terdapat di Kab. TTS. Maka sampel terkait dengan wilayah adalah wilayah Kabupaten Kupang, Kabupaten Timur Tengah Selatan dan Kabupaten Belu.

\section{METODE PENELITIAN}

\section{Pengumpulan Data}

Pengumpulan data penelitian dilakukan melalui studi perpustakaan pada dinas peternakan Provinsi Nusa Tenggara Timur antara lain: Kabupaten Kupang, Kabupaten Timor Tengah Selatan dan Kabupaten Belu Provinsi Nusa Tenggara Timur. Jenis penelitian yang digunakan merupakan penelitian studi kepustakaan untuk memperoleh gambaran tentang kenyataankenyataan kehidupan masyarakat peternak di ketiga kabupaten tersebut diatas.

\section{Metode pengumpulan data}

Data yang dikumpulkan melalui studi perpustakaan diperoleh gambaran data angka-angka mengenai populasi ternak sapi potong, sapi perah dan kerbau pada lahan pangan, hortikultural dan lahan perkebunan yang selanjutnya dilakukan analisa data.

\section{Analisis data}

1). Analisis Model matematika hubungan anatar jenis ternak ruminansia, antar jenis lahan dan antar ternak ruminansia terhadap lahan pertanian mengunakan Stef wise Regretion yang diolah melalui costat statistik.

2) Analisis Location Quotien (LQ) Hendayana (2003):

$$
\mathrm{LQ}: \frac{\mathrm{pi} / \mathrm{pt}}{\mathrm{Pi} / \mathrm{Pt}}
$$

3) Analisis Kepadatan Wilayah

$$
\mathrm{KW}=\frac{\text { Populasi Sapi Potong }(\mathrm{ST})}{\text { Luas Wilayah }(\mathrm{Km} 2)}
$$

Kriteria yang digunakan yaitu kategori sangat padat $>50$, padat $>20-50$, sedang $10-20$ dan jarang $<10$.

Penelitian ini ingin mencari (1). Model hubungan matematika populasi antar ternak ruminansia. (2). Model hubungan matematika antar jenis lahan pangan, hortikultural dan lahan perkebunan. (3) Model matematika hubungan antar jenis ternak terhadap jenis lahan pertanian. (4) Nilai LQ (Location Question) ternak ruminnsia.

\section{Populasi dan Sampel}

Populasi pada penelitian ini adalah wilayah Kabupaten Kupang, Kabupaten Timor Tengah Selatan dan Kabupaten Belu. Survei dilakukan untuk mengetahui potensi ternak sapi potong, sapi perah, dan kerbau, Luas lahan tanaman pangan, holtikultural dan lahan perkebunan yang dianalisis berdasarkan kajian hasil studi dan data sekunder yang ada.

Location Quotien (nilai parameter) untuk menentukan populasi ternak pada suatu lokasi yang menunjuk- 
kan kemampuan populasinya bisa atau tidak dijadikan sentra ternak. pi = populasi ternak 'i' pada tingkat kabupaten atau kota $\mathrm{pt}=$ populasi total kelompok ternak pada tingkat kabupaten $\mathrm{Pi}=$ populasi ternak ' $\mathrm{i}$ ' pada tingkat provinsi $\mathrm{Pt}=$ populasi total kelompok ternak pada tingkat provinsi. Kriteria yang digunakan adalah: LQ $>1$ artinya ternak 'i' di suatu wilayah telah memiliki keunggulan komparatif (populasinya melebihi kebutuhan di daerahnya sehingga bisa dijual atau diekspor ke luar wilayah). $\mathrm{LQ}=1$ artinya ternak 'i' disuatu wilayah tidak memiliki keunggulan komparatif (populasi hanya cukup untuk konsumsi sendiri). $L Q<1$ artinya ternak 'i' pada suatu wilayah tidak dapat memenuhi kebutuhan sendiri sehingga perlu pasokan dari luar wilayah.

\section{HASIL DAN PEMBAHASAN}

\section{Luas wilayah}

Luas wilayah NTT terdiri dari daratan 47.349,90 km2 dan perairan 200.00o km2. Dari seluruh wilayah Provinsi Nusa Tenggara Timur, luas lahan bukan pertanian dan lahan pertanian Kabupaten Kupang $7661.55 \mathrm{~km}^{2}$, Kabupaten Timor Tengah Selatan dengan luas $5903.5 \mathrm{~km}^{2}$, Kabupaten Belu dengan luas 9261.55 $\mathrm{km}^{2}$. Luas lahan pangan dan hortikulturl terluas Kabupaten Kupang, sedangkan luas lahan perkebunan terluas di Kabupaten Belu.

\section{Tinggi tempat}

Provinsi Nusa Tenggara Timur sebagian besar wilayahnya terdiri dari pegunungan dan berbukitbukit, dengan ketinggian antara 100-1000 $\mathrm{m}$ di atas permukaan laut berkisar 73,13\%, sisanya hanya sebagian kecil saja yang di bawah $100 \mathrm{~m}$ dan di atas $1000 \mathrm{~m}$ dari permukaan laut.

Tabel 1. Prediksi perhitungan nilai LQ (Location Quotion) ternak ruminansia Provinsi Nusa Tenggara Timur

\begin{tabular}{lccc}
\hline \multicolumn{1}{c}{ Kabupaten } & Sapi Potog & Sapi Perah & Kerbau \\
\hline Kupang & 0.119632 & 0.074229 & 6.291957 \\
TTS & 0.276214 & 1.457694 & 4.941606 \\
Belu & 0.781257 & 0.833766 & 2.076242 \\
\hline
\end{tabular}

Data ini hasil dari pengolahan data yang bersumber dari Sensus Ternak Dinas Peternakan Nusa Tenggara Timur dari tahun 2011 dan 2013 Keterangan:

LQ : Location Quotient

LQ<1 : Populasi ternak masih kurang

$\mathrm{LQ}=1 \quad$ : Populasi ternak hanya cukup untuk wilayah sendiri

LQ>1 : Populasi ternak bisa dijadikan sentra ternak untuk daerah lain

(1) Model matematika antara lahan pangan (X) terhadap populasi sapi potong (Y) didapatkan: $\mathrm{Y}=110,23238792-1,7048432552 \mathrm{X}$ dan $\mathrm{R}^{2}=$ 0,9838238238085. $(\mathrm{P}<0.01)$. (2). Model matematika antara lahan perkebunan (X) terhadap populasi sapi potong $(\mathrm{Y})$ adalah: $\mathrm{Y}=116,59960539-2,4734723692$
$\mathrm{X}$ dan $\mathrm{R}^{2}=0,983288695(\mathrm{P}<0.01)$. (3). Model matematika antara lahan hortikultural (X) terhadap populasi sapi potong $(\mathrm{Y})$ tidak berbeda nyata $(\mathrm{P}>0,05)$. Koefisien determinasi $\mathrm{R}^{2}$ sebesar 0,98 artinya bahwa hubungan antara variable bebas $\mathrm{X}$ (lahan) terhadap variabel tak bebas Y (populasi ternak) sebesar 98\% yaitu faktor variable bebas $\mathrm{X}$ (lahan) mempengaruhi variable takbebas Y(ternak) sebesr $98 \%$ dan sisanya sebesr 2\% disebabkan oleh faktor lain.

Tabel 2. Populasi Fernak Ruminansia di Tiga Kabupaten di Provinsi Nusa Tenggara Timur

\begin{tabular}{lccc}
\hline \multicolumn{1}{c}{ Kabupaten } & Sapi potong & Sapi perah & Kerbau \\
\hline Kupang & 99.607 & 3 & 868 \\
Timur tengah selatan & 109.303 & 28 & 423 \\
Belu & 115.823 & 6 & 51 \\
\hline
\end{tabular}

Sensus pertanian Provinsi Nusa Tenggara Timur tahun 2013.

Tabel 3. Luas wilayah lahan pertanian di tiga kabupaten di Provinsi Nusa Tenggara Timur

\begin{tabular}{lccc}
\hline \multicolumn{1}{c}{ Kabupaten } & Pangan & Hortikultural & Perkebunan \\
\hline Kupang & $1.441,34$ & $6.220,60$ & 575,72 \\
Timur tengah selatan & 263,35 & $5.640,17$ & 324,22 \\
Belu & $1.129,83$ & $9.369,39$ & 521,26 \\
\hline
\end{tabular}

Sensus Pertanian Provinsi Nusa Tenggara Timur tahun 2013

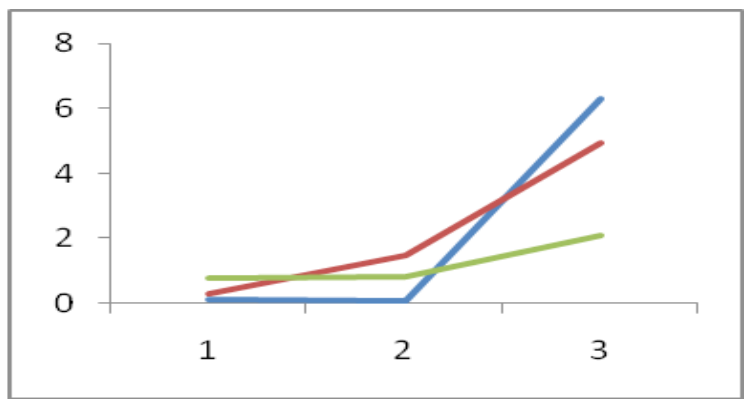

Gambar 1. Kurva nilai LQ populasi ternak di tiga Kabupaten di NTT

LQ populasi sapi potong terendah di Kabupaten Kupang, LQ populasi sapi perah juga terendah Kupang sedangkan populasi kerbau tertinggi di Kabupaten Kupang(LQ=6.291957), selanjutnya diikuti oleh Kabupaten TTS $(\mathrm{LQ}=4.941606)$ dan Kabupaten Belu populasi kerbau $(\mathrm{LQ}=2.07)$

Tabel 4. Prediksi perhitungan kepadatan wilayah ternak ruminansia di Provinsi Nusa Tenggara Timur

\begin{tabular}{lccc}
\hline \multicolumn{1}{c}{ Kabupaten } & Sapi potong & Sapi perah & Kerbau \\
\hline Kupang & 130.0023 & 5.08173 & 826.7297 \\
Timur tengah selatan & 142.6532 & 47.4295 & 308.5949 \\
Belu & 151.1667 & 10.1635 & 48.57513 \\
\hline
\end{tabular}

Keterangan:

Kriteria yang digunakan yaitu kategori sangat padat $>50$, padat $>20-50$, sedang $10-20$ dan jarang $<10$. Populasi sapi perah di Kabupaten Belu tergolong jarang. Selanjutnya di ketiga Kabupaten populasi ternak tergolong dari padat hingga sangat padat. 


\section{SIMPULAN}

Populasi ternak potong terhadap lahan pangan dan perkebunan berhubungan positif sangat nyata $\left(\mathrm{R}^{2}=\right.$ 0,98 $\mathrm{P}<0,01)$. Nilai LQ ternak kerbau terbesar berturutturut didapatkan di Kabupaten Kupang, Timor Tengah Selatan dan Belu sehingga dapat dijadikan sentra ternak kerbau untuk daerah-daerah lain di Provinsi NTT. Begitu juga untuk ternak perah di Kabupaten TTS dapat dijadikan sentra ternak karena lebih besar dari satu (LQ>1). (1) Hubungan matematika antara Lahan pangan (X) terhadap populasi sapi potong $(\mathrm{Y})$ didapatkan: $\mathrm{Y}=110,23238792-1,7048432552 \mathrm{X}$ dan $\mathrm{R}^{2}=0,9838238238085$.

(2) Hubungan matematika antara lahan perkebunan (X) terhadap populasi sapi potong $(\mathrm{Y})$ adalah: $\mathrm{Y}=$ $116,59960539-2,4734723692 X$ dan $R^{2}=0,983288695$. Slope: 2,47347, Intercept: 116,59960.

\section{UCAPAN TERIMAKASIH}

Terimakasih kami sampaikan kepada Kepala Dinas Peternakan Nusa Tenggara Timur dan Kepala Dinas Statistika Pertanian dan Peternakan Provinsi Nusa Tenggara Timur atas dukungan yang diberikan dalam pengumpulan data baik primer maupun sekunder.

\section{DAFTAR PUSTAKA}

Hendayana, R. 2003. Aplikasi Metode Location Quotient (LQ) dalam penentuan komoditas unggulan nasional. Informatika Pertanian. Volume 12: 658 - 675 .

Kadir, T.N. 2009. Program Sapi Berlian Provinsi Jawa Timur. Makalah disampaikan dalam Seminar Tematik dalam Rangka Hari Ulang Tahun. Indonesia Keluar dari Perangkap Impor Sapi Potong. Badan Penelitian dan Pengembangan Pertanian yang ke-35. Bogor, 12 Agustus 2009.

Munir, B. 2009. Implementasi Program NTB Bumi Sejuta Sapi. Makalah disampaikan dalam Seminar Tematik dalam rangka Hari Ulang Tahun. Indonesia Keluar dari Perangkap Impor Sapi Potong. Badan Penelitian dan Pengembangan Pertanian yang ke- 35. Bogor, 12 Agustus 2009.

Noor R.R. 2004. Seminar Nasional Pengembangan Peternakan Berwawasan lingkungan . IPB.Bogor.

Suryana A. 2000. Harapan dan tantangan bagi subsektor peternakan dalam meningkatkan ketahanan pangan nasional. Pros. Seminar Nasional Peternakan dan Veteriner. Bogor 18-19 September 2000. Bogor; Puslitbang Peternakan Departemen Pertanian, hal: 21- 28

Yusdja, Yusmichad, R. Sayuti, B. Winarso, I. Sadikin, dan C. Muslim. 2004. Pemantapan Program Dan Strategi Kebijakan Peningkatan Produksi Daging Sapi. Pusat Penelitian Dan Pengembangan Sosial Ekonomi Pertanian Departemen Pertanian. 